\title{
GÊNESE DE FERRI-ARGILÃS EM HORIZONTES B TEXTURAIS DE UMA SEQÜÊNCIA DE SOLOS SOBRE DIABÁSIO EM PIRACICABA (SP)
}

\author{
Miguel Cooper*; Pablo Vidal-Torrado \\ Depto. de Solos e Nutrição de Plantas - USP/ESALQ, C.P. 9 - CEP: 13418-900 - Piracicaba, SP. \\ *Autor correspondente <mcooper@carpa.ciagri.usp.br>
}

RESUMO: Numa sequência de solos sobre diabásio localizada no campus da USP em Piracicaba a formação de ferri-argilãs e os processos de adensamento foram estudados. Foram realizados estudos morfológicos, micromorfológicos, de microscopia eletrônica de varredura e microanálise em amostras retiradas de três trincheiras localizadas nesta sequência. A presença de ferri-argilãs de iluviação foi observada nos horizontes $\mathrm{B}$ textural e na alterita principalmente preenchendo a porosidade mamelonar, policôncava e fissural provocando 0 adensamento dos mesmos. Evidências de hidromorfia temporária sugeriram que este processo estaria provocando a desestabilização das ligações ferro-argila facilitando assim a mobilização e redistribuição do ferro e da argila.

Palavras-chave: Terra Roxa Estruturada, horizonte Bt, cutãs de iluviação, hidromorfia temporária, adensamento

\section{FERRIARGILLAN GENESIS IN ARGILLIC B HORIZONS OF A SOIL SEQUENCE OVER DIABASE IN PIRACICABA}

\begin{abstract}
The formation of ferriargillans and densing processes were studied on a soil sequence over diabase situated in Piracicaba (SP) Brazil. Morphological, micromorphological, scanning electron microscopic and microanalytical studies were performed on samples taken from three trenches within the sequence. The presence of illuvial ferriargillans was observed mainly in the argillic B horizons and the saprolite, which filled the mamelonar, polyconcave and planar voids which led to their densing. Evidence of temporary hydromorphy suggested that this process would affect the stability of the iron oxide-clay interactions which would promote the mobilization and redistribution of iron and clay.
\end{abstract}

Key words: Nitosols, argillic horizon, illuvial cutans, temporary hidromorphy, densing

\section{INTRODUÇÃO}

A translocação e deposição de argila na porosidade na forma de cutãs de iluviação é considerado um dos principais processos na formação de horizontes B textural. É vasta a literatura que mostra este processo como formador de horizontes $\mathrm{Bt}$ e do gradiente textural existente entre os horizontes superficiais e sub-superficiais. Eswaran \& Sys (1979) e Birkeland (1984) citam que um dos processos de formação de horizontes Bt seria a translocação de argila em suspensão na água de percolação e que se acumulariam no horizonte $B$ devido à floculação ou a constrições nos poros através dos quais a água se move. Fedoroff \& Eswaran (1985) mostram que a presença de cutãs de iluviação no horizonte B é uma das principais características para classifica-lo como B textural. Vidal-Torrado et al. (1991) estudando um Podzólico Vermelho Amarelo observaram a degradação do horizonte Bt evidenciado por mecanismo pedogenético, ocorrendo sucessivamente iluviação de argila, redução da porosidade do topo do $\mathrm{Bt}$, encharcamento temporário do topo do $\mathrm{Bt} \mathrm{e}$ degradação ou remoção lateral dos finos do topo do Bt.

Em solos com pouco ou nenhum gradiente textural a presença de cutãs de iluviação tem sido pouco estudada. Existem poucas referências na bibliografia sobre a origem de cutãs de iluviação em este tipo de solos. Estudando as propriedades micromorfológicas dos Nitossolos, Creutzberg \& Sombroek (1987) definiram uma combinação de propriedades micromorfológicas que chamaram de "Nito-argillic Syndrome", que caracterizam o horizonte nitoargílico. Dentro das características apresentadas pelos autores, destaca-se a formação de ferri-argilãs finos nos poros como sendo a feição que mais caracteriza o horizonte nito-argílico, chamando-os de "lepto-coatings". Eles explicam a formação destes "lepto-coatings" como sendo resultado da reorganização local (estresse) da argila orientada anteriormente depositada dentro do horizonte. A presença generalizada dos "lepto-coatings" no horizonte nito-argílico combinado com a ocorrência de superfícies de fraqueza no fundo matricial, podem ser considerados responsáveis pela presença de superfícies lisas e brilhantes que caracterizam o horizonte nito-argílico no campo. Estes autores reafirmam que os processos que originam a formação dos Nitossolos como a presença de alguns poucos ferri-argilãs de iluviação e uma maior abundância de "lepto-coatings" nos poros. Admitiram entretanto que a natureza exata das superfícies brilhosas nos pedes é ainda incerta (exudação, metalização, cisalhamento, e/ou iluviação), assim como a origem das formas dos pedes. 
O processo de argiluviação participa também nos processos de transformação entre horizonte com estrutura microagregada e em blocos adensada. Desta forma Lepsch et al. (1977), Fedoroff \& Eswaran (1985) e VidalTorrado (1994) observaram que a argiluviação foi um processo importante no preenchimento da porosidade de empilhamento provocando progressivamente 0 adensamento do horizonte microagregado.

O objetivo deste trabalho foi estudar a origem dos ferri-argilãs em solos com pouco ou nenhum gradiente textural e o seu papel no adensamento de horizontes microagregados.

\section{MATERIAL E MÉTODOS}

Um transeto localizado no campus da USP em Piracicaba foi escolhido para este estudo. Foram estudados os segmentos de topo e ombro desta sequência. Os solos presentes na sequência são derivados do diabásio (Formação Serra Geral) e estão classificados como Nitossolo Vermelho Eutrófico latossólico e Nitossolo Vermelho Eutrófico.

Foram abertas três trincheiras onde realizaram-se descrições morfológicas seguindo a metodologia de Lemos \& Santos (1984) modificado para maior detalhamento de certas feições e coletaram-se amostras indeformadas e orientadas dos horizontes Bt. As amostras foram impregnadas seguindo a metodologia proposta por Bénard (1996) e logo confeccionaram-se lâminas delgadas do tipo "mamute" (16 x $9 \mathrm{~cm})$. As descricões micromorfológicas seguiram os critérios propostos por Brewer (1976), Stoops \& Jongerius (1975) e Bullock et al. (1985). A partir destas amostras foram confeccionadas lâminas delgadas de formato pequeno $(4,5 \times 7 \mathrm{~cm})$ polidas para a realização de estudo de microscopia eletrônica de varredura (Benard, 1996). Um microscópio Philips XL20 acoplado com um espectrômetro de raios $X$ Link, possibilitou a observação e a caracterização química elementar de áreas e micro-sítios previamente localizados sobre as amostras. A aquisição de imagens foi efetuada em modo de elétrons retro-espalhados e nos aumentos de 166x e 825x.

\section{RESULTADOS E DISCUSSÃO}

\section{MORFOLOGIA}

Foram estudados nas três trincheiras os horizontes que apresentavam dominância de cutãs de iluviação. A diferença de outros trabalhos deste tipo, utilizou-se uma metodologia modificada de Lemos \& Santos (1984) que se caracteriza por uma descrição mais detalhada da estrutura, porosidade e atividade biológica e antrópica. $O$ detalhamento da estrutura é realizada a nível de sub-estrutura ou seja através da descrição da organização e desenvolvimento dos agregados menores (estrutura secundária) de cuja associação resulta a formação de agregados maiores (estrutura primária). Para a porosidade detalha-se a forma e tipo dos poros, e a posição onde estes ocorrem, já seja, entre os agregados, dentro dos agregados, atravessando os agregados ou dentro de material não agregado. Finalmente, o detalhamento da atividade biológica e antrópica é realizada através da observação e descrição de feições típicas destes tipos de atividades, como por exemplo a presença de pedotúbulos preenchidos ou a presença de camadas compactadas superficiais ou sub-superficiais, respectivamente.

A seguir apresentam-se os resultados das descrições morfológicas dos horizontes estudados.

\section{Trincheira 1 (topo)}

Horizonte A: profundidade $0-10 \mathrm{~cm}$; apresenta estrutura poliédrica média de $2-3 \mathrm{~cm}$ com uma subestrutura também poliédrica menos desenvolvido. Cor 2,5YR 3/3. Textura argilosa. Dentro dos agregados encontram-se partículas de quartzo limpo que não estão associados com a argila. Este horizonte apresenta uma pequena compactação nos primeiros $3 \mathrm{~cm}$ mas que não afeta o desenvolvimento das raízes. Transição gradual.

Horizonte BA: profundidade $10-30 \mathrm{~cm}$; apresenta estrutura poliédrica média e subestrutura poliédrica fina (2-3 mm) bem desenvolvida. Cor 2,5YR 3/6. Textura argilosa. Predomina a porosidade fissural entre os agregados e observa-se uma porosidade tubular menos desenvolvida que atravessa os agregados. Presença de raízes bem desenvolvidas em todo o horizonte. Transição gradual.

Horizonte Bt1: profundidade $30-70 \mathrm{~cm}$; apresenta estrutura poliédrica de tamanho centimétrico com cerosidade abundante e moderada recobrindo todos os agregados. No topo deste horizonte observa-se a presença de uma subestrutura fina $(2-3 \mathrm{~mm})$ semelhante ao do horizonte BA que desaparece a medida que descemos no horizonte. Os agregados apresentam uma forte coesão. A cerosidade observada foi classificada como sendo provavelmente originada por processos de "stress" (stresscutãs). Cor 2,5YR3 3/4. Textura argilosa. Observa-se a presença de poros tubulares, galerias preenchidas com microagregados e uma porosidade fissural entre os agregados. Dentro das galerias preenchidas com microagregados encontrou-se nódulos argilosos densos de tamanho centimétrico. Raízes se desenvolvem em todo o horizonte. Transição gradual.

\section{Trincheira 2 (ombro)}

Horizonte A: profundidade $0-16 \mathrm{~cm}$; apresenta os primeiros $2 \mathrm{~cm}$ compactados e abaixo desta compactação desenvolve-se uma estrutura poliédrica média com uma subestrutura poliédrica fina. Cor: 2,5YR 3/4. Textura argilosa. Apresenta, associado aos agregados, partículas de quartzo limpo. As raízes desenvolvem-se nas paredes dos agregados, não conseguindo penetra-los. Transição gradual. 
Horizonte BA: profundidade $16-34 \mathrm{~cm}$; horizonte muito semelhante ao correspondente na Trincheira 1. Apresenta estrutura poliédrica fina. Cor:2,5YR 3/6. Textura argilosa. Predomina a porosidade fissural entre os agregados e observa-se uma porosidade tubular menos desenvolvida que atravessa os agregados. As raízes penetram dentro dos agregados. Transição gradual.

Horizonte Bt1: profundidade 34-77 cm; apresenta estrutura poliédrica de tamanho centimétrico com cerosidade abundante e moderada recobrindo todos os agregados. Observa-se a presença de alguns revestimentos mais vermelhos que a matriz tendo uma provável origem iluvial; porém, como no perfil anterior, há uma dominância de cutãs. Cor: 2,5YR 3/6. Textura argilosa. Ocorre neste horizonte uma abundância de galerias de $5 \mathrm{~cm}$ de diâmetro; observa-se também a presença abundante de pedotúbulos preenchidos com um material mais denso, sendo que alguns apresentam orientações de argila e dos poros fissurais. Ocorre a presença de nódulos argilosos pequenos que vem dos horizontes inferiores e de fragmentos pequenos de diabásio. Transição gradual.

\section{Trincheira 3 (final do ombro)}

Horizonte A: profundidade $0-15 \mathrm{~cm}$; apresenta estrutura poliédrica de tamanho médio e friável com uma subestrutura poliédrica fina. Cor: 2,5YR 2,75/4. Textura argilosa. Apresenta uma porosidade fissural entre os agregados predominante e poros tubulares de $0,3 \mathrm{~cm}$ de diâmetro devido à atividade biológica. Observa-se a presença de seixos de quartzo e nódulos de ferro de 0,5 $\mathrm{cm}$ de diâmetro. Na superfície observa-se uma compactação de $2-3 \mathrm{~cm}$ de profundidade e que se desenvolvia mais nos locais de passagem dos animais e desaparecia embaixo dos tufos da pastagem. Presença de raízes que penetram nos agregados. A transição é gradual e ocorre numa espessura de $5 \mathrm{~cm}$ apresentando 0 desenvolvimento de uma subestrutura poliédrica pequena.

Horizonte Bt1: profundidade $15-35 \mathrm{~cm}$; apresenta estrutura poliédrica de tamanho médio e subestrutura prismática. Na parte superior do horizonte, de 15 a $25 \mathrm{~cm}$, observa-se uma subestrutura poliédrica fina. Não se observou subestrutura microagregada. A cerosidade é abundante e moderada. Cor: 2,5YR 2,75/4. Textura argilosa. Apresenta uma porosidade tubular grosseira de origem biológica e fissural dominante entre os agregados. Observa-se a presença de restos de diabásio e seixos de quartzo ( $<1 \mathrm{~mm}$ de diâmetro). As raízes penetram em todo o horizonte.

Horizonte Bt2: profundidade $50-150 \mathrm{~cm}$; apresenta estrutura poliédrica de tamanho médio com subestrutura poliédrica fina $(5 \mathrm{~mm})$ bem desenvolvida diferente dos horizontes superfíciais. Não há indícios de subestrutura microagregada. A cerosidade é abundante e moderada. Cor: 2,5YR 3/6. Textura argilosa. Apresenta uma porosidade fissural dominante, presença de muitas galerias biológicas e de pedotúbulos com preenchimentos argilosos muito densos. Observa-se a presença de nódulos litorreliquiais pequenos, menores que $1 \mathrm{~cm}$ de diâmetro, de seixos de quartzo menores que $1 \mathrm{~cm}$ e de fragmentos pequenos de diabásio. Transição gradual principalmente de cor.

Horizonte BC: Horizonte classificado como uma isoalterita. Profundidade 150-170+ cm; apresenta uma matriz amarela com uma estrutura pedomassiva e uma estrutura poliédrica não completa. Apresenta uma cerosidade abundante de cor vermelha que se distribui sobre os agregados amarelos e sobre a porosidade fissural. Cor 5YR 4/6. Textura média quase argilosa. Observa-se uma porosidade tubular e uma porosidade de dissolução entre as partículas. Presença de organizações tubulares vermelhas que apresentam estrutura microagregada. Observa-se a presença de muitas reliquias de diabásio que aumentam em profundidade. Dentro das reliquias de diabásio há cores bege claros (5YR 6/6 e 5YR $8 / 4$ ), vermelhas (5YR 4/8 e minerais pretos (2,5YR 2,5/0). Em profundidade observa-se uma estrutura de isoalterita de formato concêntrico e a presença de túbulos que a penetra contendo uma matriz muito densa e microagregada.

As descrições morfológicas mostraram uma presença importante de cerosidade que foi interpretada como podendo ser de origem iluvial ou por processos de expansão e contração formando superfícies lisas e brilhantes.

\section{MICROMORFOLOGIA}

As descrições micromorfológicas se restringiram aos horizontes Bt das trincheiras estudadas e aos horizontes de alteração da trincheira 3.

O horizonte Bt1 do perfil 1, apresenta-se muito heterogênea identificando-se três zonas diferenciadas pela sua porosidade e estrutura. Observou-se a passagem de uma zona densa de trama porfírica que apresenta agregados poliédricos subangulares, um plasma isótico e uma porosidade fissural interagregados e mamelonar intragregados dominante, para uma zona microagregada de trama enáulica, com plasma isótico e uma porosidade dominante de empilhamento. A zona intermediária de trama porfírica aberta, dominante, apresenta uma microestrutura mista com agregados poliédricos e aglomerados de microagregados, a porosidade dominante é policôncava (interagregados) e mamelonar (intragregados). Este horizonte apresenta ferri-argilãs de iluviação $(20 \%)$ localizados principalmente na porosidade policôncava e de empilhamento (Figura 1), alguns deles foram modificados pelos movimentos de massa do solo e apresentam orientação manchada. Observam-se cutãs de difusão de ferro nas bordas de alguns agregados.

O horizonte Bt1 do perfil 2 apresenta duas zonas com trama porfírica que se diferenciam no desenvolvimento da porosidade mamelonar e policôncava. 
A zona mais densa apresenta agregados poliédricos subangulares mas dentro dos poros cavitários observa-se a presença de microagregados. A porosidade dominante nesta zona é a fissural enquanto que na zona menos densa são os poros policôncavos e mamelonares. $O$ plasma é isótico. Observa-se a presença de ferri-argilãs (20\%) distribuídos dentro da porosidade policôncava, mamelonar e fissural. A presença de cutãs de difusão, neocutãs e pápulas evidenciam uma possível movimentação de ferro e da massa do solo.

O horizonte Bt1 do perfil 3 apresenta duas zonas porfíricas que foram diferenciadas principalmente pela cor e pela porosidade. A zona dominante apresenta uma cor vermelha escura, uma microestrutura caracterizada por agregados poliédricos subangulares com pedalidade moderada a fraca e uma porosidade dominante mamelonar. A outra zona apresenta cores brunasavemelhadas, agregados poliédicos subangulares com uma pedalidade moderada. A porosidade desta zona e predominantemente fissural apresentando, também, poros mamelonares e cavidades biológicas. O plasma na zona vermelho escuro apresenta-se isótica, enquanto que na bruno-avermelhada ela é isótica com algumas áreas vossépicas e argilassépicas Observou-se a presença de ferri-argilãs (15\%) preenchendo principalmente os poros mamelonares e fissurais.

A lâmina da alterita (Trincheira 3 , horizonte $B C$ ) mostra duas zonas bem definidas com uma transição gradual entre elas. A primeira delas corresponde a uma zona de alteração formada por um alteroplasma com birrefringência argilassépica de cor bruna e bruna amarelada composta principalmente por plagioclásios alterados e caulinita. Apresenta uma trama pórfiro-enáulica e a porosidade é dominada por fissuras e poros mamelonares. A segunda corresponde a um pedoplasma argilassépico e isótico de cor avermelhada e brunoavermelhada que apresenta uma trama porfírica e pórfiroenáulica. A microestrutura é formada por agregados poliédricos subangulares e aglomerados de microagregados. A porosidade é dominada por poros mamelonares e policôncavos e alguns canais e cavidades biológicas e fissuras. Ocorre presença de ferri-argilãs de iluviação preenchendo os poros mamelonares, fissurais e policôncavos.

A partir da descrição micromorfológica observouse que os ferri-argilãs estão localizados principalmente na porosidade mamelonar intragregados e na porosidade fissural provocando, também, o adensamento material. Estes estão localizados nos horizontes mais superficiais onde a drenagem é menor desaparecendo nos horizontes mais porosos. Na trincheira 3 estão espalhados por todo o perfil observando-se a presença destes inclusive na alterita. A presença de cutãs de difusão, ferrãs e em alguns locais a presença de um plasma vossépico, evidenciaria processos de segregação e migração de ferro provavelmente devido a períodos curtos de hidromorfia.

\section{CARACTERÍSTICAS SUBMICROSCÓPICAS E MICROANALÍTICAS}

A presença de cutãs de iluviação, classificados neste caso como ferri-argilãs, foi constatada em todos os perfis estudados, distribuídos principalmente nos horizontes Bt e na parte superior da alterita do perfil 3. Nos estudos micromorfológicos observou-se que estes apresentavam uma orientação forte contínua, uma cor vermelha mais clara que o fundo matricial e estavam distribuídos principalmente dentro da porosidade policôncava e mamelonar e nas fissuras.

$O$ estudo detalhado nas resoluções do microscópio eletrônico de varredura mostrou que os cutãs preenchiam grande parte da porosidade mamelonar provocando uma coalescência do fundo matricial e o conseqüente adensamento (Figura1). Este processo de deposição, como já foi dito, começa nas parte superiores da camada de alteração. Não foi possível observar uma orientação preferencial das argilas nesta escala. Embora que a maioria dos cutãs apresentou uma orientação forte e contínua na escala do microscópio ótico. Uma grande porção dos ferri-argilãs apresentava-se fissurada, devido às forças de contração e expansão do solo, explicando, desta forma, a orientação manchada destes nas observações com o microscópio ótico.

Foi realizado um estudo comparativo da composição elementar entre os materiais que compõem os ferri-argilãs e o fundo matricial do solo (TABELA 1). Verificou-se que na alterita a composição só variava no teor de ferro, ou seja, os materiais, tanto do cutã como do fundo matricial, eram cauliníticos mas o cutã apresentava mais ferro. A medida que se passa para os horizontes mais pedogenéticos a situação muda. Observa-se que na transição entre a alterita e o horizonte $\mathrm{B}$, o horizonte $\mathrm{BC}$, os dois materiais continuam a ser cauliníticos, mas o teor de Fe do cutã não muda em relação ao da alterita e o teor é variável deste elemento no fundo matricial. Nos horizontes Bt de subsuperfície, neste caso foi exemplificado com o horizonte T2 Bt2, praticamente não existe diferença entre a composição dos cutãs e o fundo matricial.

A análise desta informação resulta em duas interpretações. Na primeira, devido à semelhança na composição dos cutãs da alterita com os dos horizontes pedogenéticos $(\mathrm{Bt})$ e à diferença destes cutãs com o fundo matricial local, evidencia-se, somente no perfil 3, uma translocação e deposição de argila dos horizontes Bt para a alterita. $\mathrm{Na}$ segunda, a semelhança da composição dos cutãs e do fundo matricial dentro dos horizontes Bt de todos os perfis estudados sugere uma redistribuição local da argila associada ao ferro provocando a formação dos ferri-argilãs nos poros policôncavos e mamelonares.

\section{INTERPRETAÇÃO GERAL}

A presença generalizada de cutãs de iluviação (ferriargilãs) distribuídos nos horizontes Bt e preenchendo a porosidade policôncava e mamelonar, sugere que este processo participa no adensamento destes horizontes. A 


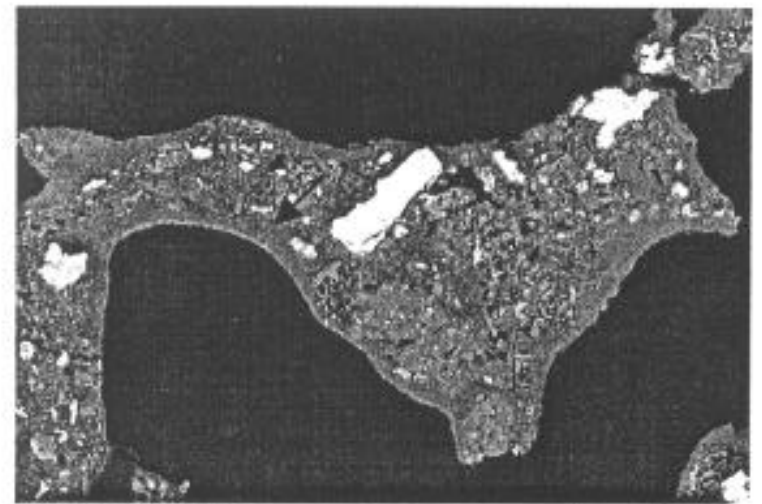

a) $\mathrm{T} 3$ alteração

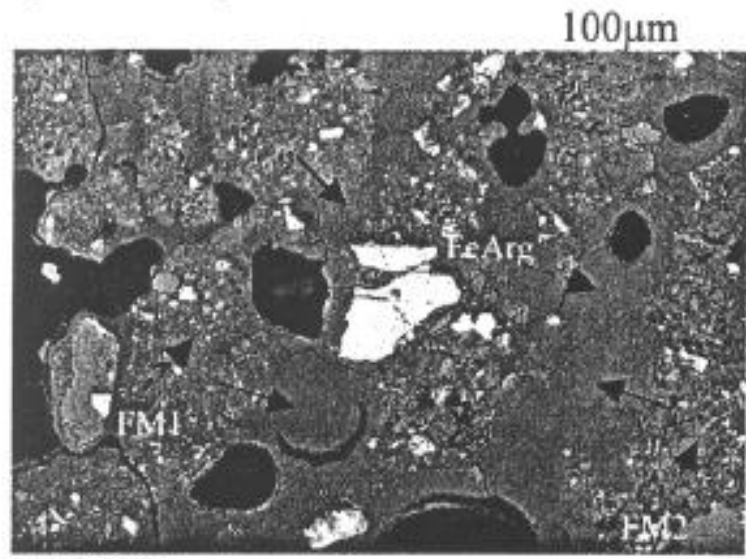

c) $\mathrm{T} 3 \mathrm{BC}$

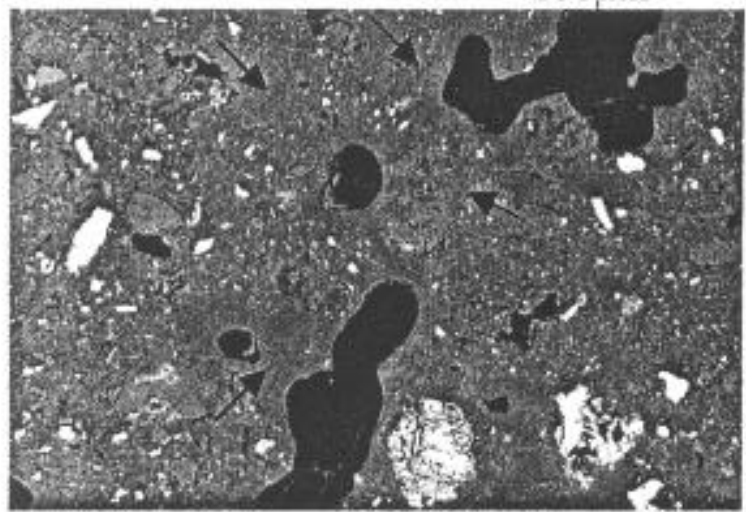

e) $\mathrm{T} 1 \mathrm{Bt} 2$

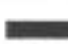

100 um

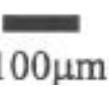

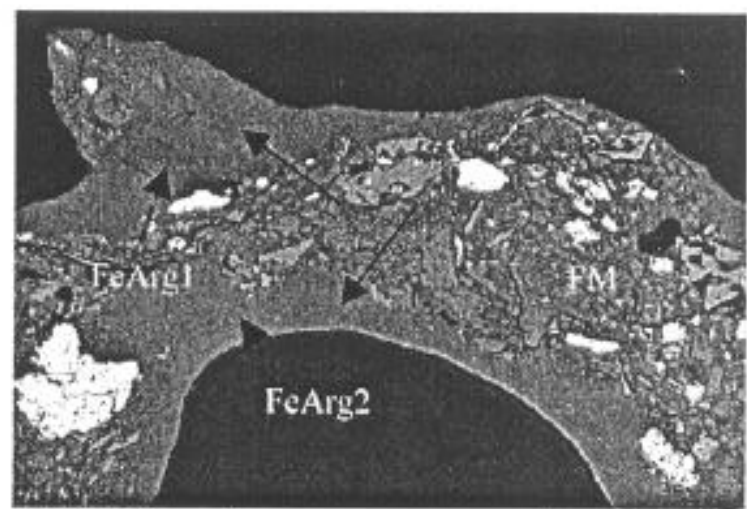

b) T3 alteração

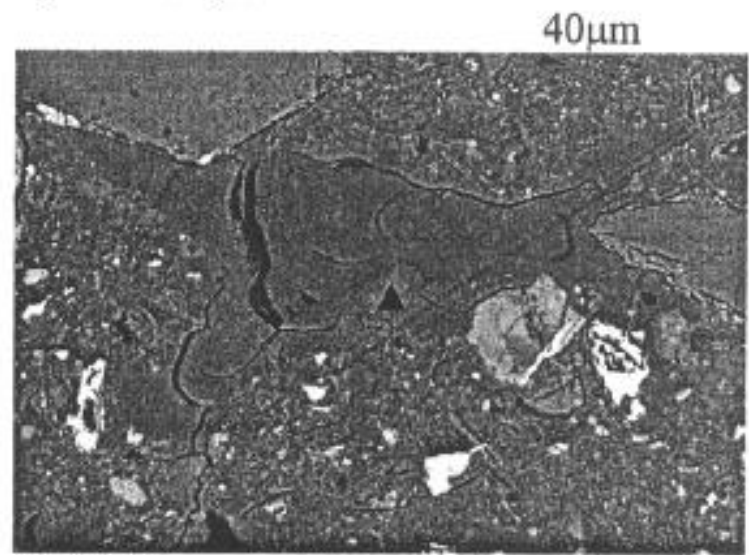

d) $\mathrm{T} 3 \mathrm{Bt} 3$

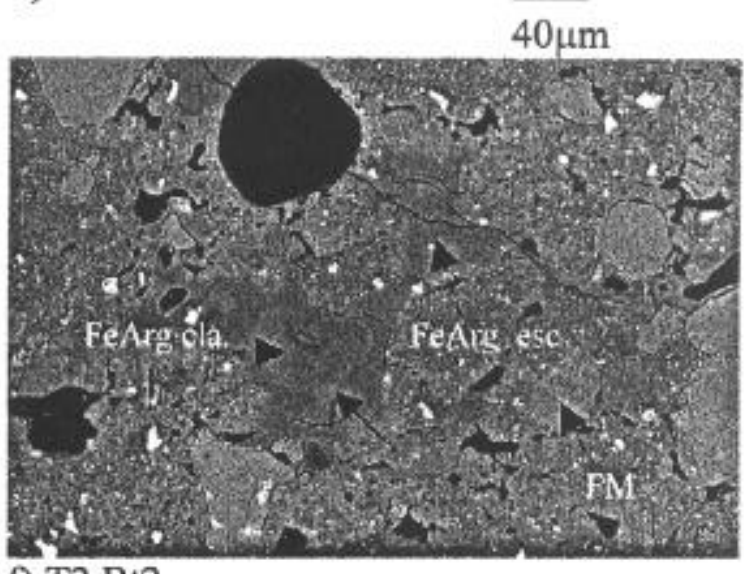

f) $\mathrm{T} 2 \mathrm{Bt} 2$

$100 \mu \mathrm{m}$

Figura 1 - Cutãs de iluviação (setas pretas) preenchendo a porosidade e adensando o material. Setas tracejadas, ponto de microanálise: $\mathrm{FeArg}=$ ferri-argilã, $\mathrm{FM}=$ fundo matricial, esc $=$ escuro, $\mathrm{cla}=$ claro

constatação de períodos curtos de saturação nos horizontes densos superficiais da sequência (Cooper, 1999), como consequência da redução do espaço poral ocorrida durante a fase anterior de adensamento por coalescência de microagregados, provocaria um hidromorfismo temporário que promoveria a remoção de ferro, evidenciada pela identificação de cutãs de difusão, neocutãs, quasicutãs e nódulos ferruginosos, e a desestabilização das ligações ferro-argila facilitando assim a mobilização da argila e do ferro (Lepsch et al., 1977; Queiroz Neto et al., 1981; Vidal Torrado, 1994).

Scientia Agricola, v.57, n.4, p.745-750, out./dez. 2000 
TABELA 1 - Composição elementar dos ferri-argilãs e fundo matricial de três zonas diferentes.

\begin{tabular}{|c|c|c|c|c|c|c|c|c|c|c|c|c|c|c|}
\hline & $\mathrm{Na}$ & $\mathrm{Mg}$ & $\mathrm{Al}$ & $\mathrm{Si}$ & $\mathrm{P}$ & $S$ & $\mathrm{Cl}$ & $\mathrm{K}$ & $\mathrm{Ca}$ & $\mathrm{Ti}$ & $\mathrm{Cr}$ & $\mathrm{Mn}$ & $\mathrm{Fe}$ & $\mathrm{O}$ \\
\hline & & & & & & & ---- & & & & & & & \\
\hline \multicolumn{15}{|l|}{ Alteração } \\
\hline Ferriargilã 1 & 0 & 0,2 & 17,9 & 21,7 & 0,4 & 0 & 1 & 0,1 & 0,3 & 0,4 & 0 & 0 & 12,2 & 45,5 \\
\hline Ferriargilã 2 & 0,1 & 0,2 & 18,1 & 21,8 & 0,5 & 0,1 & 1,2 & 0,1 & 0,3 & 0,4 & 0 & 0 & 11,3 & 45,8 \\
\hline Fundo matricial & 0 & 0,2 & 18,5 & 24,9 & 0,6 & 0 & 2,6 & 0 & 0,3 & 0,1 & 0 & 0,1 & 4,4 & 48 \\
\hline \multicolumn{15}{|l|}{ T3 BC } \\
\hline Ferriargilã & 0 & 0,1 & 17,2 & 20,5 & 0,4 & 0,1 & 0,9 & 0 & 0,4 & 0,5 & 0 & 0 & 15,3 & 44,4 \\
\hline Fundo matricial 1 & 0 & 0,1 & 18,2 & 22,8 & 0,3 & 0,1 & 0,8 & 0 & 0,3 & 0,2 & 0 & 0,2 & 10,5 & 46,3 \\
\hline Fundo matricial 2 & 0 & 0,1 & 20,6 & 26,5 & 0,1 & 0 & 0,5 & 0,1 & 0,2 & 0 & 0 & 0 & 2,3 & 49,6 \\
\hline \multicolumn{15}{|l|}{$\mathrm{T} 2 \mathrm{Bt} 1$} \\
\hline Ferriargilã escuro & 0,1 & 0 & 18,6 & 20,3 & 0,4 & 0 & 0,6 & 0 & 0,1 & 0,6 & 0 & 0 & 14,4 & 44,7 \\
\hline Ferriargilã claro & 0,2 & 0 & 18,8 & 20,2 & 0,3 & 0,1 & 0,6 & 0 & 0,1 & 0,7 & 0 & 0 & 14 & 43,9 \\
\hline Fundo matricial & 0,3 & 0 & 19,1 & 19,9 & 0,3 & 0,2 & 0,6 & 0 & 0,1 & 0,7 & 0 & 0 & 13,7 & 43,5 \\
\hline
\end{tabular}

\section{CONCLUSÕES}

Os cutãs de iluviação (ferriargilãs) teriam a sua origem nos processos de hidromorfia temporária que ocorrem nos horizontes superficiais e Bt dos solos, provocando a desestabilização das ligações ferro-argila facilitando assim a mobilização e redistribuição do ferro e da argila.

O preenchimento da porosidade pelos cutãs de iluviação, evidencia a sua participação no processo de adensamento dos horizontes Bt.

\section{AGRADECIMENTOS}

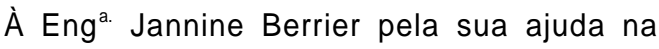
obtenção das imagens no microscópio eletrônico de varredura, o Departamento de Solos e Nutrição de Plantas da ESALQ/USP e à USARQ (Unite de Sol-Agronomie de Rennes-Quimper) do INRA de Rennes, França pelo uso dos laboratórios e as suas instalações, à FAPESP e CAPES pelas bolsas concedidas ao primeiro autor.

\section{REFERÊNCIAS BIBLIOGRÁFICAS}

BÉNARD, Y. Les techniques de fabrication des lames minces de sol. Cahiers Techniques INRA, v.37, p.29-42, 1996.

BIRKELAND, P.W. Soils and geomorphology. New York: Oxford University Press, 1984. 372p.

BREWER, R. Fabric and mineral analysis of soils. New York: Robert E. Krieger Publishing, 1976. 482p.

BULLOCK, P.; FEDOROFF, N.; JONGERIUS, A.; STOOPS, G.; TURSINA,T. Handbook for soil thin section description. Albrington: Waine Research, 1985. 152p.

COOPER, M. Influência das condições físico-hídricas nas transformações estruturais entre horizontes $b$ latossólico e $b$ textural sobre diabásio, Piracicaba, 1999. 127p. Tese (Doutorado) - Escola Superior de Agricultura "Luiz de Queiroz", Universidade de São Paulo.
CREUTZBERG, D.; SOMBROEK, W.G. Micromorphological characteristics of Nitosols. In: RÉUNION INTERNATIONALE DE MICROMORPHOLOGIE DES SOLS, 7., Paris, 1985. Actes. Paris: Association Française pour l'Etude du Sol, 1987. p.151-155.

ESWARAN, H.; SYS, C. Argillic horizon in LAC soils: formation and significance to classification. Pedologie, v.29, p.175-190, 1979.

FEDOROFF, N.; ESWARAN, H. Micromorphology of ultisols. In: DOUGLAS, L.A.; THOMPSON, M.L. Soil micromorphology and soil classification. Madison: SSSA, 1985. p.145-164.

LEMOS, R.C. DE; SANTOS, R.D. DOS Manual de descrição e coleta de solo no campo. Campinas: SBCS/SNLCS, 1984. 46p.

LEPSCH, I.F.; BUOL, S.W.; DANIELS, R. Soil landscape relationships in the occidental plateau of São Paulo, Brazil: II. Soil morphology, genesis and classification. Soil Science Society of America Journal, v.41, p.109-115, 1977.

QUEIROZ NETO, J.P.; CASTRO, S.S.; FERNANDES BARROS, O.N.; MANFREDINI, S.; RUELLAN, A.; TOLEDO, G.S. Um estudo de dinâmica de solos: formação e transformação de perfis com horizonte B textural. In: CONGRESSO BRASILEIRO DE CIÊNCIA DO SOLO, 18., Salvador, 1980. Resumos. Campinas: SBCS, 1981. p.150-154.

STOOPS, G.; JONGERIUS, A. Proposal for a micromorphological classification in soil materials: I. A classification of the related distributions of coarse and fine particles. Geoderma, v.13, p.189-200, 1975.

VIDAL TORRADO, P. Pedogênese e Morfogênese no Distrito de Tupi (Piracicaba-SP). Piracicaba, 1994. 205p. Tese (Doutorado) - Escola Superior de Agricultura "Luiz de Queiroz", Universidade de São Paulo.

VIDAL TORRADO, P.; MAZZA, J.A.; CASTRO, S.S.; DEMATTÊ, J.L.I. Micromorfologia e gênese de um Podzólico Vermelho Amarelo desenvolvido de sedimentos da formação Itararé no distrito de Tupi (Piracicaba-SP). In: CONGRESSO BRASILEIRO DE CIÊNCIA DO SOLO, 23., Porto Alegre, 1991. Resumos. Campinas: SBCS, 1991. p.275.

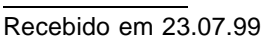

